\title{
Tuberous sclerosis complex
}

INSERM

\section{Source}

INSERM. (1999). Orphanet: an online rare disease and orphan drug data base. Tuberous sclerosis complex. ORPHA:805

Tuberous sclerosis complex (TSC) is a neurocutaneous disorder characterized by multisystem hamartomas and associated with neuropsychiatric features. 